\title{
ELECTROCHEMICAL DESALINATION OF NaCI SOLUTIONS BY ELECTROSORPTION ON NANO-POROUS CARBON AEROGEL ELECTRODES
}

\author{
D. MARMANIS ${ }^{1}$ \\ A. CHRISTOFORIDIS ${ }^{1}$ \\ K. OUZOUNIS ${ }^{2}$ \\ K. DERMENTZIS ${ }^{1, *}$
}

\author{
${ }^{1}$ Department of Petroleum and Natural Gas Technology \\ Laboratory of Environment Protection \\ Kavala Institute of Technology, 65404 Agios Loucas, Kavala, Hellas \\ ${ }^{2}$ Department of Environmental Engineering \\ Laboratory of Environmental Chemistry \\ Democritus University of Thrace, 67100 Xanthi, Hellas
}

Received: 02/10/2013

Accepted: 23/05/2014

Available online: $27 / 05 / 2014$ *to whom all correspondence should be addressed: e-mail: demerz@otenet.gr

\section{ABSTRACT}

The objective of this study is to elucidate the efficiency of electrosorption on desalination of aqueous NaClsolution using nano-structured carbon aerogel electrodes. The experiments were performed in an electrosorption cell consisting of a pair of carbon aerogel sheets separated by a $0.5 \mathrm{~cm}$ spacer. The electrosorption performance is investigated with different applied voltages and solution concentrations. It increases with increasing applied voltage, higher concentration gradient and less double-layer overlapping effect. Under the experimental conditions at the optimum applied voltage of 1.2 Volt and initial $\mathrm{NaCl}$ concentration $100-1000 \mathrm{mg} \mathrm{l}^{-1}$, the electrosorption capacity was found to be $5.20-14.22 \mathrm{mg}$ $\mathrm{NaCl} / \mathrm{g}$ carbon aerogel. $\mathrm{Na}^{+}$and $\mathrm{Cl}^{-}$ions are electro-absorbed at the electrical double layer without electron transfer redox reactions at anode and cathode. The good electrosorption performance of carbon aerogel electrodes might be attributed to their high specific area, high electrical conductivity, chemical inertness and optimal pore size distribution for the passage and easy movement of ions during electrosorption and electrodesorption. The process is reversible, as the electrode charge/discharge procedure can be repeated innumerable times without any significant loss of salt sorption capacity in all cycles.

Keywords: Electrochemical desalination; electrosorption - electrodesorption; carbon aerogel electrodes

\section{Introduction}

Electrodeionization is the removal of ions and ionizable species from water or organic liquids. It uses electrically active media and an electrical potential to cause ion transport and may be operated continuously or batch wise. Continuous processes, such as electrodialysis (ED) (Abou-Shaby et al., 2011; DiMachio et al., 1998; Willauer et al., 2011; Zhang et al., 2011), and filled cell electrodialysis or otherwise called continuous electrodeionization(CEDI) (Arar et al., 2013; Lu et al., 2011) comprise alternating permselective cation exchange membranes and anion exchange membranes. Under the influence of the electric field only cations and only anions, respectively are allowed to permeate their mass, while simultaneously co-ions are retained. In this way diluate and concentrate compartments are created and deionization occurs. Electrostatic shielding electrodialysis (ESED) uses ionic current sinks instead of ion exchange membranes to create the necessary diluate and concentrate compartments (Dermentzis, 2010; Dermentzis et al., 2012).

Marmanis D., Christoforidis A., Ouzounis K. and Dermentzis K.(2014), Electrochemical desalination of $\mathrm{NaCl}$ solutions by electrosorption on nano-porous carbon aerogel electrodes, Global NEST Journal, 16(4), 609-615. 
Batch electrodeionization processes such as capacitive deionization (CDI) or otherwise called electrosorption (Cohen et al., 2011; Demirer et al.,2013; Jung et al., 2007; Zhang et al., 2011) and membrane capacitive deionization (Biesheuvel \& van der Val, 2010; Lee et al., 2011) are collection / discharge processes which rely on the formation of double-layer supercapacitorat the solution/electrode interface. When an electric field is applied between two electrodes, ions in the solution are forced to move towards to the opposite charged electrodes, resulting in purification of the treated solution. CDI dates back to the mid-1960s and early 1970s when porous electrodes made of activated carbon powder were used in a flow-through capacitor for water desalination (Oren, 2008). CDI is the most economic and energy efficient method of water deionization. It needs porous nano-sized electrodes with very large specific area, such as carbon aerogels (Gabelich et al., 2002), carbon nanotubes and nanofibres (Wang et al., 2006), or activated nano-structured carbon cloths (Ahn et al., 2007) to increase the salt sorption capacity. The costly high specific area electrodes and the fact that the process could not be turned to a continuous one remain the main drawbacks of this technology.

Carbon aerogel electrodes exhibit an excellent electrosorption performance due to their high specific area, high electrical conductivity, chemical inertness and optimal pore size distribution. Therefore, these electrodes have proved to be unique materials for electrochemical removal of salt from brackish or seawater (Cohen et al., 2011; Gabelich et al., 2002; Jung et al., 2007). Furthermore, these electrodes have been tested for removal of other charged contaminants from industrial wastewater, such as heavy metal ions (Rana et al., 2004; Yiacoumi et al., 2000) and ionic or ionizable organics (Wu et al., 2008).

The contribution of the present research is: $\alpha$ ) to present the fundamental aspect of the electrosorption/electrodesorption process; b) to provide a critical review of the advantages and limitations of capacitive deionization; and c) to elucidate the efficiency of capacitive deionization on desalination of aqueous $\mathrm{NaCl}$ solutions using nano-structured carbon aerogel electrodes. All operating parameters affecting the electrosorption performance, such as applied voltage, solution concentration and solution $\mathrm{pH}$ are examined and the electrosorption capacity of $\mathrm{NaCl}$ on carbon aerogel electrodes is investigated.

\section{Materials and methods}

\subsection{Electrochemical cell}

All experiments were carried out in a $100 \mathrm{ml}$ rectangular laboratory glass vessel with dimensions $10 \mathrm{~cm}$ in length, $10 \mathrm{~cm}$ in height and $1 \mathrm{~cm}$ in width. Two sheets of carbon aerogel electrodes (Marketech Int. USA) with dimensions $8 \mathrm{~cm}$ in height and $8 \mathrm{~cm}$ in width each were used as anode and cathode. The electrodes were placed vertically parallel to each other at a distance of $0.5 \mathrm{~cm}$ between them. The solution volume was $30 \mathrm{ml}$. A saturated calomel electrode (SCE) was used as a reference electrode. Proper provisions were made in the lid of the glass vessel for fixing the anode, the cathode and the bridge of the reference electrode.

The carbon aerogel electrodes were used as received. Their main properties, as supplied by the manufacturer, are listed in Table 1.

Table 1. Main characteristics of carbon aerogel electrodes

\begin{tabular}{ll}
\hline Parameter & Value \\
\hline Surface area & $600 \mathrm{~m}^{2} \mathrm{~g}^{-1}$ \\
\hline Average pore size & $75-80 \mathrm{~nm}$ \\
\hline Density & $0.4-0.5 \mathrm{~g} \mathrm{~cm}^{-3}$ \\
\hline Capacitance & $28-30 \mathrm{~F} \mathrm{~g}^{-1}$ \\
\hline Resistivity & $0.01-0.04 \Omega \theta \mathrm{cm}$ \\
\hline
\end{tabular}




\subsection{Apparatus}

A DC power supply (Agilent E3612A, USA) was used for measuring the electrode potential and current. The experiments were conducted at room temperature. The $\mathrm{NaCl}$ concentrations were determined by measuring the electrical conductivity of the treated $\mathrm{NaCl}$ solution. A linear relationship existing between $\mathrm{NaCl}$ concentration and conductivity via a calibration curve was made prior to electrosorption experiments, which is depicted in Figure 1. The values of conductivity in $\mu \mathrm{S} \mathrm{cm}^{-1}$ are about twice higher than those of concentration in $\mathrm{mg} \mathrm{l}^{-1}$.

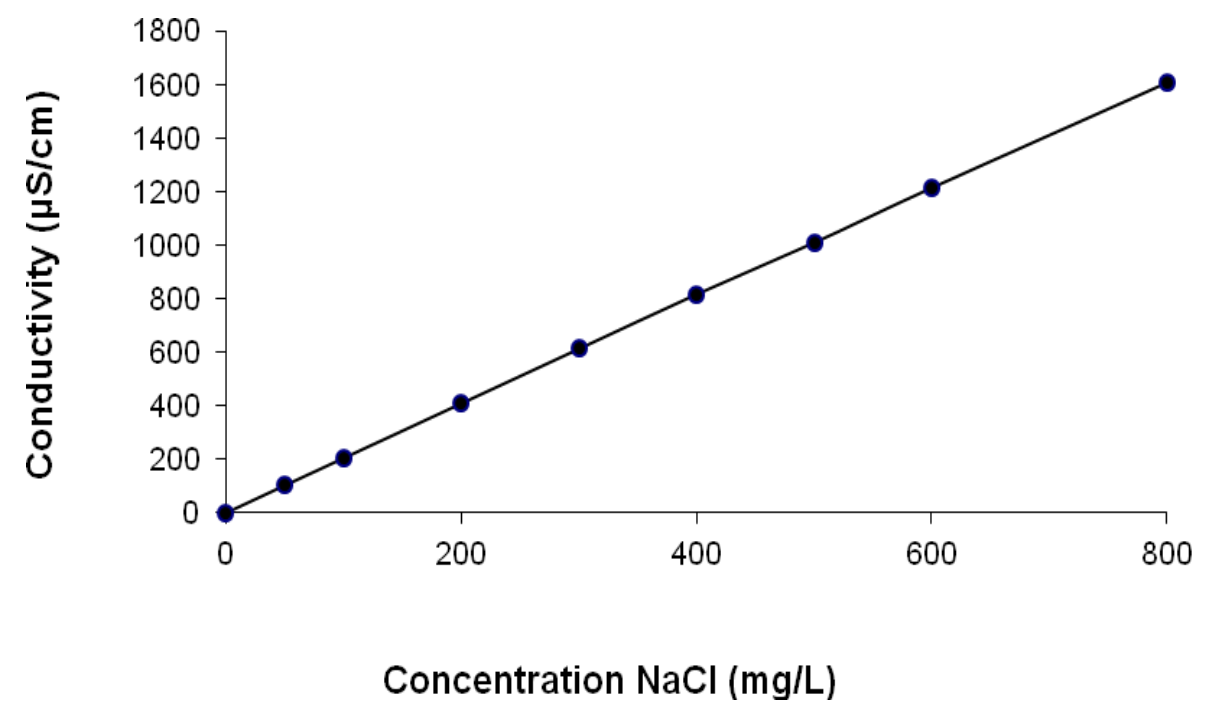

Figure 1. Conductivity versus concentration of dilute $\mathrm{NaCl}$ solutions.

Conductivity was measured by means of a conductometer (WTW). $\mathrm{pH}$ and temperature were determined using a pH-meter (Hanna) connected to a combined electrode comprising a temperature sensor.

The salt electrosorption capacity (q) defined as the quantity of $\mathrm{NaCl}$ electro-absorbed per unit mass of carbon aerogel was determined using Equation (1):

$$
q=\frac{\left(\begin{array}{ll}
\text { Co } & C
\end{array}\right) \mathrm{V}}{\mathrm{m}}
$$

where

$\mathrm{C}_{0}$ and $\mathrm{C}$ are the solution concentrations of $\mathrm{NaCl}$ at the beginning and at any time $\left(\mathrm{mg} \mathrm{l}^{-1}\right)$, respectively, $\mathrm{V}$ is the solution volume $(\mathrm{I})$ and $\mathrm{m}$ is the mass of carbon aerogel electrode (g).

\section{Results and discussion}

The main factors affecting the electrosorptive deionization are the applied potential and the initial solution concentration, i.e. initial $\mathrm{NaCl}$ concentration.

\subsection{Effect of applied potential}

To study the effect of applied potential (voltage) on $\mathrm{NaCl}$ removal experiments were carried out under varying voltages of $0,0.6$ and $1.2 \mathrm{~V}$ at fixed $\mathrm{NaCl}$ concentration of $100 \mathrm{mg} \mathrm{I}^{-1}$, neutral $\mathrm{pH}=7$ and $30 \mathrm{~min}$ time run. The results are shown in Figure 2. The initial conductivity of $205 \mu \mathrm{S} \mathrm{cm}^{-1}$ of the treated $\mathrm{NaCl}$ solution decreased to 194,130 and $38 \mu \mathrm{Sm}^{-1}$ at the corresponding applied voltage of $0.0,0.6$ and $1.2 \mathrm{~V}$, respectively. 
Higher removal efficiency for $\mathrm{NaCl}$ was achieved at higher voltages. This is a presumable phenomenon as increased voltage increases the flow velocity of electrons and the electrostatic attraction of ions by the opposite charged electrodes.

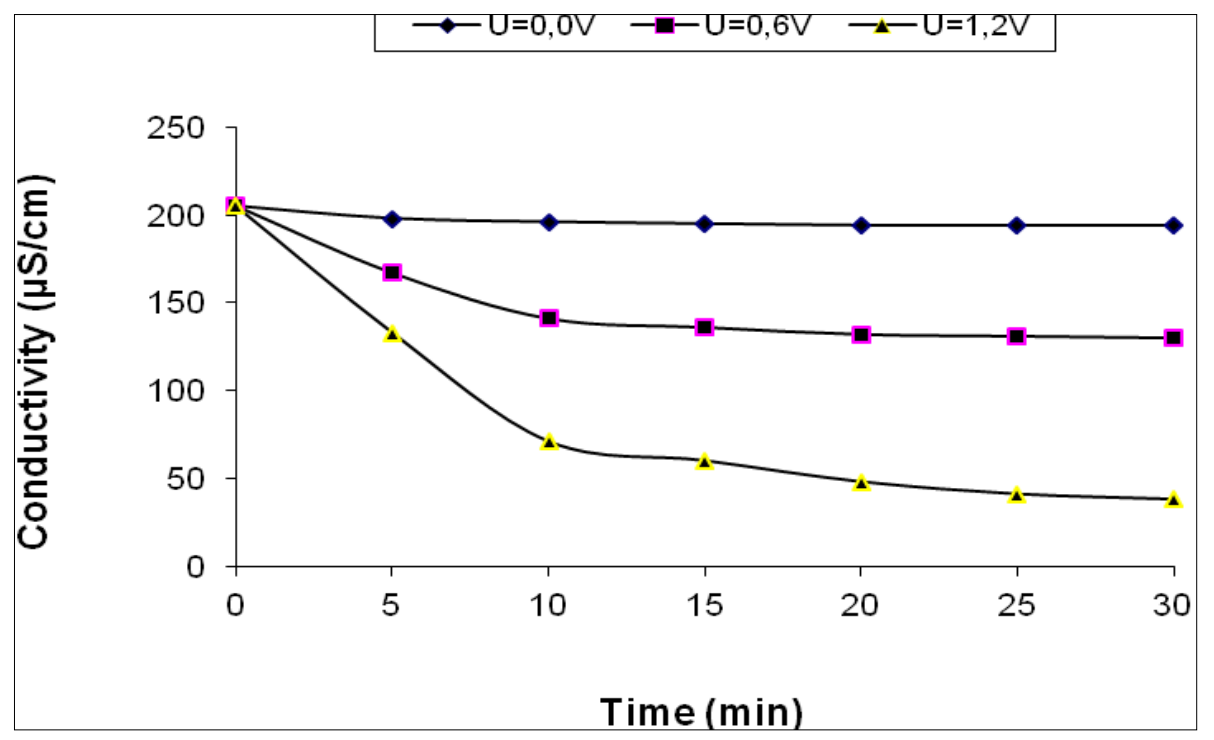

Figure 2. Conductivity variation versus time at various applied voltages.

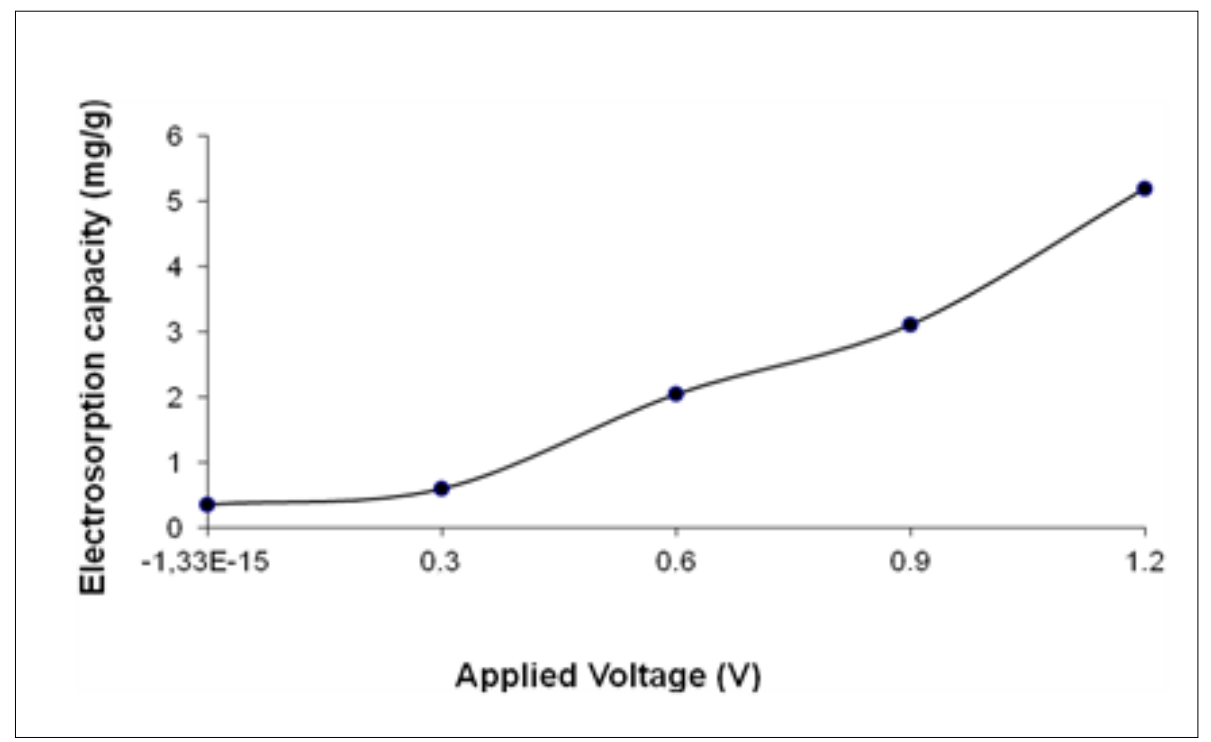

Figure 3. Electrosorption capacity of $\mathrm{NaCl}$ on carbon aerogel versus applied voltage.

The observed $\mathrm{pH}$ drop from 7 to 5.65 during the open-circuit adsorption of $\mathrm{NaCl}$ at $0.0 \mathrm{~V}$ provides evidence for ion exchange phenomena between $\mathrm{Na}^{+}$and $\mathrm{H}^{+}$ions, which take place on the carbon aerogel surface. During the electrosorption process at 0.6 and $1.2 \mathrm{~V}, \mathrm{pH}$ increases only slightly, namely to 6.37 and 6.88 , respectively.

At voltages higher than the electrochemical decomposition potential of water (1.23 V) higher removal efficiency of $\mathrm{NaCl}$ could be achieved. However, partially water electrolysis to hydrogen and oxygen gas due to $\mathrm{H}^{+}$and $\mathrm{OH}^{-}$ion discharge at the cathode and anode, respectively, could be observed. For this reason the electrodes were polarized at voltages not higher than $1.2 \mathrm{~V}$. 
The salt electrosorption capacity calculated from Equation 1, amounts to $0.35,0.59,2.04,3.11$ and 5.20 $\mathrm{mg}^{-1} \mathrm{NaCl}$ per $\mathrm{g}$ carbon aerogel for the applied voltages of $0.0,0.3,0.6,0.9$ and $1.2 \mathrm{~V}$, respectively (Figure 3).

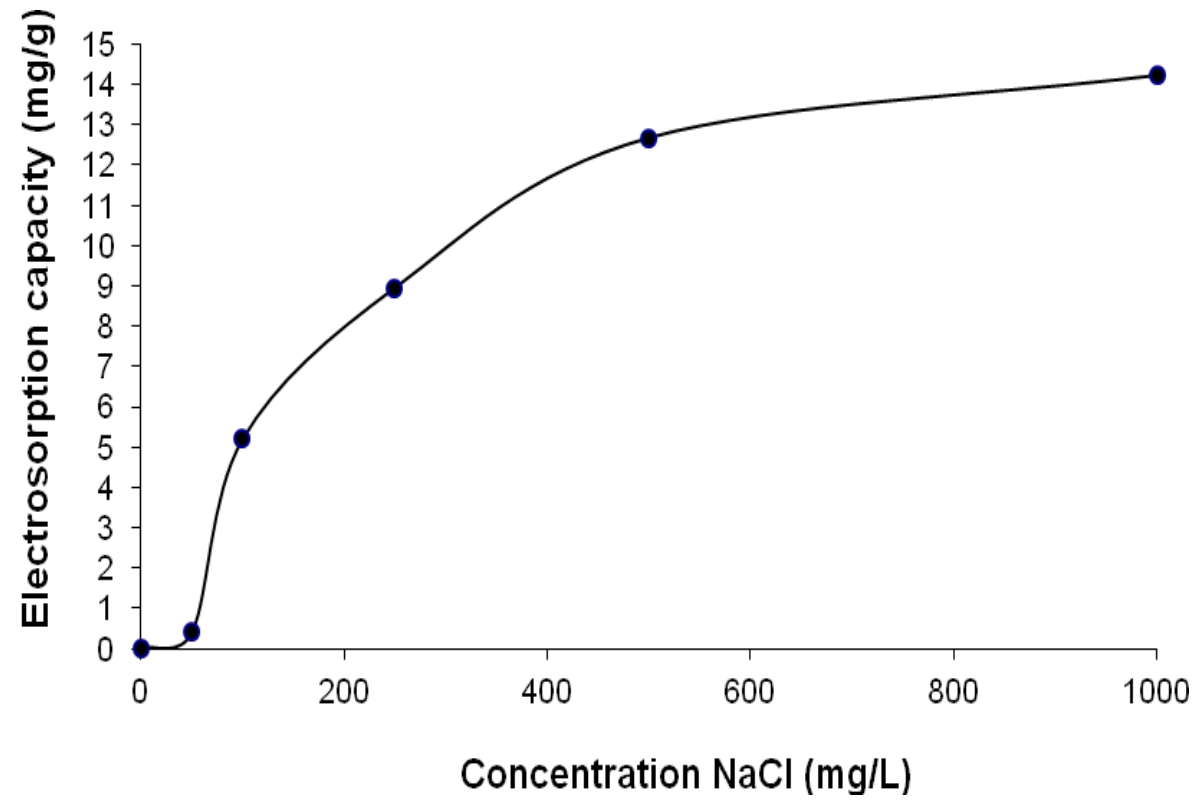

Figure 4. Electrosorption capacity of $\mathrm{NaCl}$ on carbon aerogel versus $\mathrm{NaClinitial} \mathrm{concentration}$

\subsection{Electrodesorption and electrode regeneration}

The electrodesorption process helps to regenerate the electrodes and recover the adsorbed $\mathrm{NaCl}$ from the electrodes. Regeneration of electrodes can be accomplished by two modes, namely discharging the cell at $0.0 \mathrm{~V}$ or reversing the cell polarity at an opposite charge. In the first mode a considerable amount of the electrical energy stored in the capacitor can easily be recovered during the regeneration step. In this way, capacitive deionization is an electrochemical means of saving electrical energy and delivering clean water (Anderson et al., 2010). In the second mode of reverse polarization the regeneration effectiveness and the electrode reactivation are increased.

The charged carbon aerogel electrodes were sort-circuited and depolarized to $0.0 \mathrm{~V}$. The absorbed $\mathrm{Na}^{+}$ and $\mathrm{Cl}^{-}$ions were released from the cathode and the anode, respectively, and the solution conductivity rapidly reached its initial value. Almost $100 \%$ of $\mathrm{NaCl}$ could be recovered by the electrodesorption/regeneration step. The electrosorption/electrodesorption procedure is a rapid and reversible process, which can be repeated innumerable times without any significant loss of salt sorption capacity in all cycles, as known from electrochemical double layer supercapacitors (Kötz \& Carlen, 2000). Ions are electrostatically held on the electric double layer during polarization and released from it during depolarization of the electrodes. In practice, no undesirable ion discharge through faradaic electron transfer redox reactions take place at the electrode/solution interface.

The good electrosorption/electrodesorption performance of carbon aerogel electrodes might be attributed to their high specific area, high electrical conductivity, chemical inertness and optimal pore size distribution for the passage and easy movement of ions during the electrosorption and electrodesorption steps.

\section{Conclusions}

In this work, the performance of capacitive deionization for desalination of dilute aqueous $\mathrm{NaCl}$ solutions using carbon aerogel electrodes was investigated. Carbon aerogel electrodes with the high specific area, optimal pore size distribution and high electrical conductivity are unique electrode 
materials for double layer capacitors and electrosorption of ions. The deionization mechanism relies on electrostatic interactions between charged electrodes and ions and formation of electric double layer on the carbon aerogel surface. The low applied potential ensures non faradaic capacitive currents without electron transfer redox reactions at the electrode/solution interface and furthermore, low electrical energy consumption, most of which can also be recovered in the electrode regeneration step. Charge and discharge of the electrodes can be repeated boundlessly without any significant loss of the salt sorption capacity. It was found that the electrosorption capacity increased by increasing the applied voltage due to stronger electrostatic attraction. Voltages higher than the electrochemical decomposition potential of water $(1.23 \mathrm{~V})$ should not be applied in order to avoid the undesirable hydrogen and oxygen gas evolution at the cathode and the anode respectively. The electrosorption capacity increased sharply by increasing the initial $\mathrm{NaCl}$ concentration in the range $0-500 \mathrm{mg} \mathrm{I}^{-1}$, due to higher concentration gradient, reaching the value of $12.67 \mathrm{mg} \mathrm{NaCl}$ per g of carbon aerogel. Furthermore, it increased only slightly to $14.22 \mathrm{mg} \mathrm{l}^{-1}$ at $1000 \mathrm{mg} \mathrm{l}^{-1} \mathrm{NaCl}$. It can be concluded that capacitive deionization is potentially attractive for desalination of low salinity brackish and surface waters.

\section{References}

Abou-Shaby A., Peng C., O J.A. and Xu H. (2011), Effect of $\mathrm{pH}$ on separation of $\mathrm{Pb}$ (II) and $\mathrm{NO}_{3}{ }^{-}$from aqueous solutions using electrodialysis, Desalination, Doi: 10.1016/j.desal.2011.09.032.

Ahn H-J., Lee J-H., Jeong Y., Lee J-H., Chi C-S. and Oh H-J. (2007), Nanostructured carbon cloth electrode for desalination from aqueous solutions, Material Science Engineering A, 449-451, 841-845.

Anderson M.A., Cudero A.L. and Palma J. (2010), Capacitive deionization as an electrochemical means of saving energy and delivering clean water. Comparison to present desalination practices: Will it compete?, Electrochimimica Acta, 55, 3845-3856.

Arar O., Yuksel U., Kabay N. and Yuksel M. (2013), Application of electrodeionization (EDI) for removal of boron and silica from reverse osmosis (RO) permeate of geothermal water, Desalination, 310, 25-53.

Bieshevel P.M. and van der Val A. (2010), Membrane capacitive deionization, Journal of Membrane Science, 346, 256-262.

Cohen I., Avraham E., Noked M., Soffer A. and Aurbach D. (2011), Enhanced charge efficiency in capacitive deionization achieved by surface-treated and by means of a third electrode, Journal of Physical Chemistry $C$, 115, 19856-19863.

Demirer O.N., Naylor R.M., Rios Perez C.A., Wilkes E. and Hidrovo C. (2013), Energetic performance optimization of a capacitive deionization system operating with transient cycles and brackish water, Desalination, 314, 130-138.

Dermentzis K. (2010), Removal of nickel from electroplating rinse waters using electrostatic shielding electrodialysis/electrodeionization, Journal of Hazardous Materials, 173, 647-652.

Dermentzis K., Davidis A., Chatzichristou C. and Dermentzi A. (2012), Ammonia removal from fertilizer plant effluent streams by an electrostatic shielding based coupled electrodialysis/electrodeionization process, Global NEST Journal, 14, 468-476.

DiMascio F., Wood J. and Fenton J. (1998), Continuous electrodeionization, Production of high-purity water without regeneration chemicals, Electrochemical Society Interface, 7, 26-29.

Gabelich C.J., Tran T.D. and Mel-Suffetl. H. (2002), Electrosorption of inorganic salts from aqueous solution using carbon aerogels, Environmental Science and Technology, 36, 3010-3019.

Jung H.H., Hwang S-W., Hyun S-H., Lee K-H. and Kim G-T. (2007), Capacitive deionization characteristics of nanostructured carbon aerogel electrodes synthesized via ambient drying, Desalination, 216, 377-385.

Kötz R. and Carlen M. (2000), Principles and applications of electrochemical capacitors, Electrochimiica Acta, 45, 2483-2498.

Lee J-Y., Seo S-J., Yun S-H. and Moon S-H. (2011), Preparation of ion exchanger layered electrodes for advanced membrane capacitive deionization (MCDI), Water Research, 45, 5375-5380.

Lu H.X., Wang J.Y., Bu S.F., Zhang M.Q. and Zhang J.B. (2011), Removal of nickel ions from dilute heavy metal solution by electrodeionization process, Advanced Material Research, 183-185, 580-584. 
Oren Y. (2008): Capacitive deionization (CDI) for desalination and water treatment - past, present and future (a review), Desalination, 228, 10-29.

Rana P., Mohan N. and Rajagopal C. (2004), Electrochemical removal of chromium from wastewater by using carbon aerogel electrodes, Water Research 38, 2811-2820.

Wang X.Z., Li M.G., Chen Y.W., Cheng R.M., Huang S.M., Pan L.K. and Sun Z. (2006), Electrosorption of ions from aqueous solutions with carbon nanotubes and nanofibers composite film electrodes, Applied Physics Letters, 89, 053127.

Willauer H.D., Di Mascio F., Hardy D.R., Lewis M.K. and Williams F.W. (2011), Development of an electrochemical acidification cell for the recovery of $\mathrm{CO}_{2}$ and $\mathrm{H}_{2}$ from seawater, Industrial and Engineering Chemistry Research, 50, 9876-9882.

Wu X., Yang X., Wu D. and Fu R. (2008), Feasibility study of using carbon aerogel as particle electrodes for decolorization of RBRX dye solution in a three-dimensional electrode reactor, Chemical Engineering Journal, 138, 47-54.

Yiacoumi S., Ying T.Y. and Yang K-L. (2000), Electrosorption of metal ions from aqueous solutions, Technical Report, Oak Ridge National Laboratory, 1-14.

Zhang L., Zuo D., GuoS.L., Cao Z., Liu J., MengQ.J. and Yu X.Y. (2011), Electrosorptive deionization based on activated carbon capacitor prepared from bamboo char, Advanced Materials Research, 233-235, 378-381.

Zhang Y., Ghyselbrecht K., Meesschaert B., Pinoy L. and Van der Bruggen B. (2011), Electrodialysis on RO Concentrate to Improve WaterRecovery in Wastewater Reclamation, Journal of Membrane Science, 378, 101-110. 